\title{
Venezuela: luces y sombras de un desarrollo alternativo
}

Venezuela, con casi 30 millones de habitantes y algo más de 916 mil $\mathrm{km}^{2}$, vive una experiencia que, en la última década y media, la ha convertido en protagonista principal en América Latina y el Caribe y a nivel internacional. El discurso, la política y la práctica que emanan de su gobierno, principalmente de su presidente -quien ejerce un liderazgo fuerte-, son un referente obligado para el desarrollo alternativo crítico en la región. Han surgido nuevos espacios de poder, nuevos sujetos sociales y nuevas áreas geopolíticas que deben conocerse, analizarse y discutirse de la manera más desprejuiciada posible.

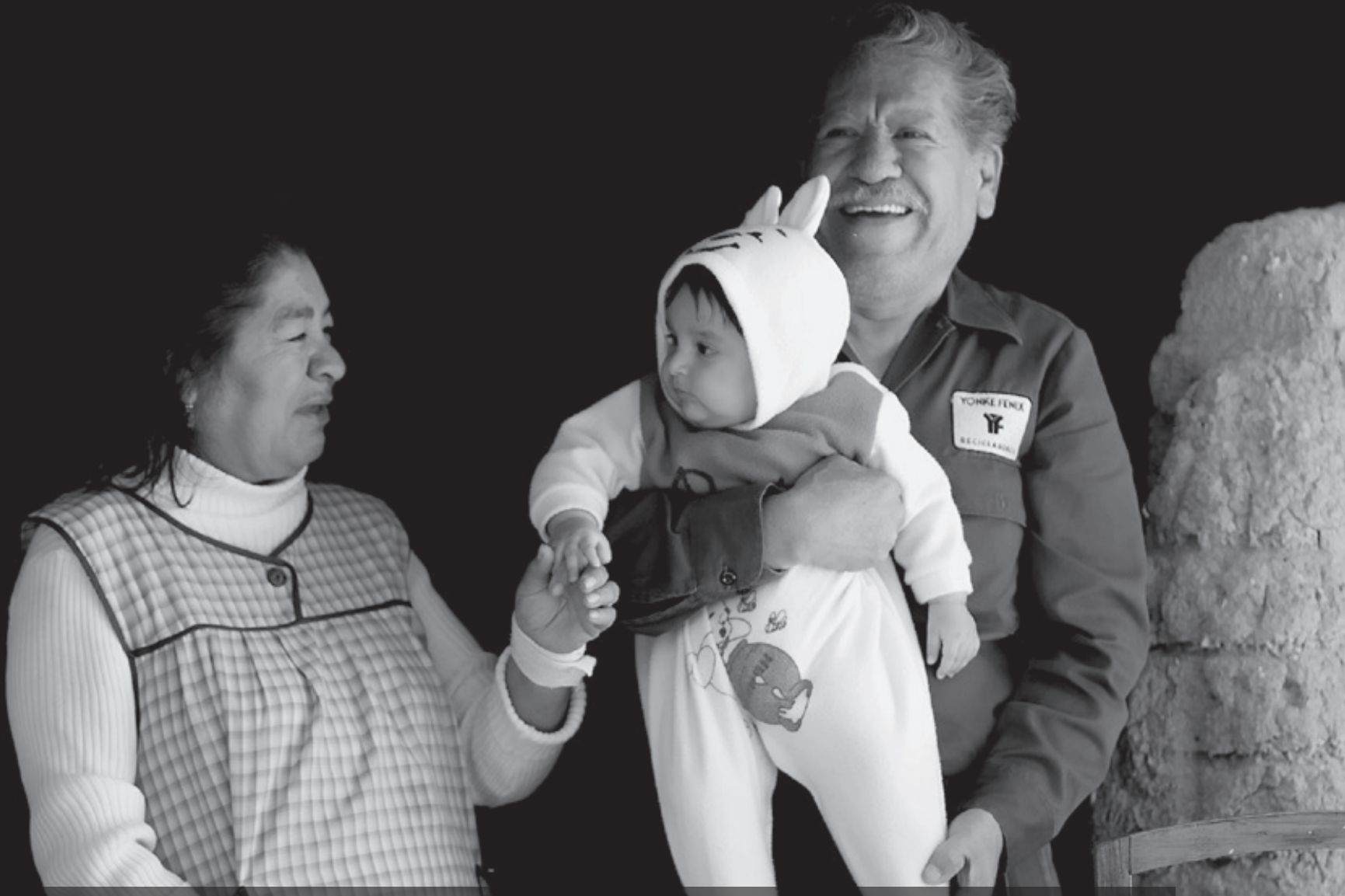

José Déniz es docente-investigador de la Unidad Académica de Estudios del Desarrollo de la Universidad Autónoma de Zacatecas, México. 
Desarrollo alternativo

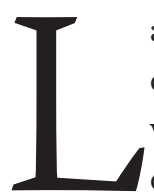
a actual realidad mundial evidencia que se está conformando un nuevo ciclo histórico que, no obstante, aún conserva la naturaleza y la lógica de funcionamiento del sistema capitalista. En esta transición coexisten unas tendencias que indican la constitución de nuevos escenarios y actores, junto a la incertidumbre sobre sus visiones, significado y comportamiento final. Hasta ahora no hay un relevo claro en las relaciones multilaterales, aunque se visualicen unas hegemonías que se van debilitando y otras que se van construyendo y fortaleciendo.

Estas transformaciones son diversas y van acompañadas de fuertes tensiones, cuyas dinámicas responden a los propios acontecimientos que acaecen y a la contestación a los mismos. La gran concentración de poder y riqueza en simultaneidad con el aumento y multiplicidad de las desigualdades ha creado tales contradicciones que están propiciando respuestas alternativas, en el pensamiento y la acción de los movimientos sociales y políticos. Los resultados desestabilizadores de las políticas de ajuste neoliberal contribuyen grandemente a que, en el caso de América Latina y el Caribe (ALC), hayan surgido experiencias de construcción de alternativas de desarrollo crítico con características muchas veces inéditas; alternativas que se presentan como más eficaces, dado que se piensa que son capaces de crear empleo y generar un bienestar social más justo y satisfactorio para las necesidades humanas, debido a que se basan en otras relaciones sociales. A diferencia del neoliberalismo, que defiende la idea de que las economías deben ser más competitivas en el exterior, basándose en la explotación de sus trabajadores, con bajos salarios y exclusión de amplios sectores de la población, se contrapone el objetivo de consolidar el mercado interior como base endógena del modelo productivo, con una distribución del ingreso y la riqueza más equitativa, lo que a su vez hará más justa la inserción internacional. Por primera vez en la región, con pocos años de diferencia, van accediendo a los gobiernos nacionales o locales de algunos países organizaciones que - si bien tienen trayectorias, ideologías y liderazgos diversos- convergen en algunos rasgos básicos orientados a la transformación.

En los años recientes, movimientos sociales y partidos de izquierda han resurgido con una fuerza que no se preveía, por lo que se ha hablado de una nueva izquierda. Esta denominada nueva izquierda lo es no sólo por tener un origen o capacidad de movilización más reciente sino también por diferenciarse de la izquierda histórica o que le ha precedido. ${ }^{1}$ De cualquier manera, para que germinara esta nueva izquierda en ALC, además de una serie de factores ocurridos en su propio terreno, es necesario recordar que emerge en un escenario donde objetivamente se hacían sentir los estragos de las políticas económicas y sociales del neoliberalismo. Los partidos políticos tradicionales sufrían un gran descrédito y crisis, dejando espacios vacíos y, a la vez, habían surgido nuevos actores políticos y formas de movilización social, algunos de los cuales sustituyeron el papel que habían cumplido los sindicatos o algunas formaciones políticas.

A pesar de que estas experiencias son muy diversas y la complejidad de la realidad latinoamericana es muy alta, es posible detectar rasgos comunes que caracterizan a esta nueva izquierda; a la cual, en todo caso, es más correcto calificar en plural, como izquierdas, debido a sus diferencias en múltiples dimensiones. En grandes y muy estilizados términos, dichos rasgos son: 1) pluralidad de estrategias y articulación de formas organizativas descentralizadas; 2) multiplicidad de bases sociales y agendas políticas; 3) relieve de la sociedad civil; 4) reformismo, y 5) profundización de la democracia.

Esta enumeración estaría incompleta si no se añaden algunas consideraciones que tienen que ver, más singularmente, con la alternativa poscapitalista que fomentan algunos gobiernos de ALC en la última década y media. El primero en hacerlo fue Hugo Chávez, en febrero de 1999, cuando asume la presidencia de Venezuela - luego convertida en República Bolivariana de Venezuela (RBV)—, para luego promover el llamado socialismo del siglo XXI, a cuya estrategia se añaden, posteriormente, otros gobiernos del área. El único gobierno de la región que se definía como socialista era el cubano, que desde hace décadas ha estado inscrito en la histórica tradición de esta corriente de izquierda, lo cual no ha impedido que forme parte de esta nueva circunstancia política en la que tiene destacada influencia.

Hace casi noventa años, José Carlos Mariátegui expresó que «no queremos ciertamente que el socialismo sea en América calco y copia» ${ }^{2}$ y, apoyándose en Marx, precisó que la búsqueda de «un nuevo proyecto estratégico alternativo en Latinoamérica» hace necesario comprender lo que está más allá de los paradigmas vigentes en el siglo xx y sobreponerse a «dogmas y prejuicios». Desde este supuesto, puede apreciarse que 
el presente proyecto histórico sólo podrá ser «un socialismo nuevo, democrático, participativo, construido desde abajo y en permanente apertura a los cambios, a las innovaciones por parte del pueblo protagonista».

Dicho lo anterior, cabe preguntarse ¿en qué medida, como desarrollo alternativo crítico, el socialismo del siglo xxi que se promueve en y desde la RBV responde a lo dicho anteriormente? En los párrafos siguientes se aportarán algunos datos y referencias que se consideran dignos de atención para poder avanzar en la caracterización de la experiencia venezolana a la fecha.

\section{LA REALIDAD \\ ECONÓMICA Y SOCIAL}

El 6 de diciembre de 1998, Hugo Chávez triunfó por vez primera en las elecciones presidenciales y puso fin al bipartidismo que había nacido en 1958 con el Pacto de Punto Fijo entre los dos partidos principales, Acción Democrática ( $\mathrm{AD}$, socialdemócrata) y el Comité de Organización Política Electoral Independiente (COPEI, socialcristiano), que se habían alternado en el gobierno hasta 1993, cuando Rafael Caldera asumió la presidencia mediante un partido creado para esos efectos, aunque él proviniera del último de los partidos citados.

El triunfo electoral de este militar de carrera fue el resultado de un dilatado proceso de algo más de dos décadas y compuesto de múltiples circunstancias. En 1977 creó el Ejército Bolivariano Revolucionario (EBR) y en 1982 el Movimiento Bolivariano Revolucionario-200 (MBR-200). Esta última denominación se debe a la fecha de natalicio del libertador Simón Bolívar, nacido en Caracas, cuyo bicentenario se cumpliría al año siguiente. Esta figura histórica es la explícita referencia desde el inicio mismo del proyecto político de Chávez. Con este movimiento, integrado con oficiales y suboficiales de carrera, realizó el fallido golpe de Estado el 4 de febrero de 1992 y el golpe del 27 de noviembre del mismo año. El MBR-200, convertido en unión cívico-militar, dio origen en 1997 al Movimiento v República (MVR), el partido político de Chávez.

Desde 1996, con la llamada Agenda Alternativa Bolivariana (AAB) se proyecta y promueve una asamblea constituyente para que impulse —como se proclamó- una revolución democrática, participativa y pacífica. Convocar a una constituyente se convirtió en un instrumento habitual en los posteriores movimientos políticos afines de otros países de la región. Las reformas constituyentes han sido estratégicas y han permitido, desde los gobiernos, cambiar estructuras y políticas que cuestionan el poder hasta entonces existente. Con esta bandera, la candidatura presidencial de Chávez en 1998 fue apoyada por la izquierda electoral en su conjunto, con la excepción de pequeñas organizaciones. Un par de meses después del triunfo electoral se convocó a referéndum a fin de modificar la Constitución vigente desde 1961, con un resultado muy favorable; el nuevo texto fue redactado por la Asamblea Nacional Constituyente, luego se aprobó en referéndum y entró en vigor el 30 de diciembre de 1999.

A partir de este nuevo orden jurídico y normativo se han realizado numerosas convocatorias electorales en poco más de una década, lo cual ha ocurrido en pocos países. La primera de ellas fue el 30 de julio de 2000, donde Chávez obtuvo un triunfo muy amplio. En abril de 2002 sufrió un golpe de Estado, que logró revertir, pero que dejó su impronta política en los años subsiguientes, sin que ello impidiera continuar con la política de convocatorias de referéndum y elecciones periódicas. En 2008 se creó el Partido Socialista Unido de Venezuela (PSUV), a partir del MVR y otras estructuras políticas afines, que se ha constituido en el partido de gobierno y que representa su proyecto en las citas electorales, cuya última expresión fueron las elecciones de octubre de 2012, donde volvió a triunfar el presidente Chávez frente a un candidato común de la oposición.

La trayectoria de estos años, con los principios y valores que han guiado este desarrollo alternativo crítico, pero también con el gran aporte del carisma y el liderazgo del presidente, puede ser evaluada a partir de los resultados concretos, que en este caso serán sólo los indicadores económicos y sociales, aunque de evidente relevancia. Las fuentes estadísticas corresponden a los datos más recientes de las publicaciones oficiales, como el Instituto Nacional de Estadística (INE) y el Ministerio del Poder Popular para la Comunicación y la Información (MPPCI). ${ }^{3}$ Los indicadores que se presentan son los siguientes: ${ }^{4}$ regularización de la tenencia de la tierra, aumento de la superficie cosechada, incremento de la producción agropecuaria, acrecentamiento del consumo de alimentos, mejoría en la tasa de empleo y más empleo formal, menor tasa de inflación, tasa de crecimiento del PIB muy irregular, mejoría salarial, mejor distribución del ingreso, reducción de la pobreza, más cobertura de la seguridad social, mejoría sanitaria, mejoría educativa y mayor soberanía y difusión tecnológica. 
que indica el INE venezolano, dado que utilizan metodologías diferentes.

A su vez, la pobreza se redujo de manera muy considerable, y esa magnitud es lo revelador en el caso venezolano, puesto que igual tendencia se ha dado en toda la región. Seguramente que en este país esto se explica por varios factores, entre los que sobresalen las políticas activas de los programas de las llamadas «misiones» y el aumento de los ingresos laborales, aprovechando los buenos precios petroleros en el mercado mundial durante gran parte de estos años. Asimismo, mejoró la calidad de vida de la población, sobre todo de parte de aquellos muchos que accedieron al agua potable, entre otros servicios, aunque todavía sobrevengan déficit por superar.

\section{REFLEXIONES FINALES}

Con los elementos de juicio de los párrafos anteriores, se puede reflexionar sobre la experiencia de desarrollo venezolana de esta casi década y media. ¿Cuánto tiene de desarrollo y cuánto de desarrollo alternativo? En cuanto a lo primero, cualquiera sea la conceptualización de desarrollo que se asuma, es objetivamente comprobable que se ha producido significativos avances en los indicadores que se han recogido, que no son simplemente ta- sas de crecimiento - sin menospreciarlas - sino que se incrementó el bienestar y la calidad de vida de amplios sectores de la población.

En cuanto a lo segundo, es necesario diferenciar las visiones y las políticas alternativas dentro del sistema de las que lo son al mismo sistema. En el caso de la RBV, lo que se ha llevado a cabo hasta ahora perfectamente se encuadra como una alternativa contraria al imperante capitalismo neoliberal, pero asumible por el propio sistema (algunos hablan de un capitalismo de Estado con fuerte peso de las políticas distributivas), dado que no ha roto sustancialmente con la naturaleza y lógica del proceso capitalista de acumulación de capital. Sin embargo, es también evidente que explícitamente se pretende superar al propio sistema, definiéndose como anticapitalista, por lo tanto como un proyecto alternativo a dicho sistema, que sería, en el lenguaje oficial, el socialismo del siglo xxi, que todavía está en proceso de construcción como modelo y como práctica.

Más aún, al interior del propio bloque bolivariano se pueden identificar varios puntos de vista que, hasta ahora, controla el liderazgo indiscutible del presidente Chávez. La correlación de fuerzas que pueda derivarse de la dinámica de los acontecimientos y al interior del propio proceso marcará el futuro inmediato del mismo y, por lo tanto, de la alternatividad del proyecto bolivariano.

\section{Notas}

1 José Déniz, La experiencia venezolana como un caso de desarrollo alternativo, Madrid, Fondo de Cultura Económica, 2013 (en prensa).

2 Isabel Rauber, América Latina. Poder y socialismo en el siglo XXI, Valencia y Caracas, Vadell Hermanos Editores, 2006, pp. $15-16$.

3 INE (Instituto Nacional de Estadística), Resumen de Indicadores Socioeconómicos, Caracas, 2011, 〈www.ine.gov.ve〉; MPPCI (Ministerio del Poder Popular para la Comunicación y la Infor- 